\title{
Adhesions and endometriosis: challenges in subfertility management
}

\section{(An expert opinion of the ANGEL-The ANti-Adhesions in Gynaecology Expert PaneL- group)}

\author{
R. L. De Wilde ${ }^{1}$ - J. Alvarez ${ }^{2}$ - H. Brölmann ${ }^{3}$ R. Campo ${ }^{4}$ - Y. Cheong ${ }^{5}$.

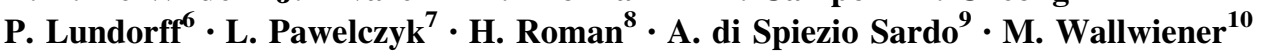

Received: 26 January 2016/ Accepted: 11 February 2016/Published online: 19 February 2016

(c) Springer-Verlag Berlin Heidelberg 2016

\begin{abstract}
There is molecular evidence that endometriosis has a negative impact on the ovaries, although the exact pathophysiology concerning endometriosis-associated subfertility is not known. The negative impact on the tuboovarian unit can be directly by distorting the anatomy, indirectly by invoking inflammation or by oxidative damage with poorer-quality oocytes. Endometriosis even seems to have a negative effect on pregnancy outcome after in vitro fertilization.
\end{abstract}

Keywords Adhesions - Endometriosis - Subfertility management $\cdot$ Adhesion prophylactic agents

Endometriosis is a common, chronic and enigmatic disease. Its exact prevalence is unknown, but up to $10 \%$ of the general female population and up to $50 \%$ of subfertile women could be affected [1,2]. Women complaining of

Under the auspices of the ESGE Adhesions Research Special Interest Group (European Society of Gynecological Endoscopy).

The members of the ANGEL Group are given in Acknowledgments.

\section{R. L. De Wilde}

rudy-leon.dewilde@pius-hospital.de

1 Clinic of Gynecology, Obstetrics and Gynecological Oncology, University Hospital for Gynecology, Pius-Hospital Oldenburg, Medical Campus University of Oldenburg, Oldenburg, Germany

2 Hospital Universitario Infanta Sofía, Paseo de Europa, 34, 28702 San Sebastián de Los Reyes, Spain

3 Department of Obstetrics and Gynecology, VU University, 1081 Amsterdam, The Netherlands

4 Leuven Institute for Fertility and Embryology (LIFE), Tiensevest 168, 3000 Louvain, Belgium infertility are six to eight times more likely to have endometriosis compared to fertile women [3]. There is molecular evidence that endometriosis has a negative impact on the ovaries [4], although the exact pathophysiology concerning endometriosis-associated subfertility is not known. The negative impact on the tubo-ovarian unit can be directly by distorting the anatomy [5], indirectly by invoking inflammation $[6,7]$ or by oxidative damage [8] with poorer-quality oocytes [9]. Endometriosis even seems to have a negative effect on pregnancy outcome after in vitro fertilization $[10,11]$.

Endometriosis, due to its inflammatory nature, is an adhesiogenic disease. Its recurrent nature means that repeated surgeries are often required, which leads to further adhesion formation [12]. For these reasons, adhesions and endometriosis are two connected entities and adhesion prevention in endometriosis treatment should be considered important [13].

The economic burden of endometriosis is heavy (0.8-12.5 billion euros per country and year in Europe) and comparable to other chronic diseases such as diabetes [14].

5 Human Development and Health Unit, University of Southampton and Complete Fertility Centre, Southampton, UK

6 Department of Obstetrics and Gynecology, Privathospitalet Mølholm, 7100 Vejle, Denmark

7 Division of Infertility and Reproductive Endocrinology, Poznan University of Medical Sciences, Poznan, Poland

8 Hopitaux De Rouen, Clinique Gynecologique et Obstetricale, 1 Rue Germont, 76031 Rouen Cedex, France

9 Studio medico, via San Giacomo dei Capri 63, Naples, Italy

10 Department of Obstetrics and Gynecology, University Clinic Heidelberg, 69120 Heidelberg, Germany 
Endometriosis has significant negative impact on social, familial, sexual, educational and professional aspects of the daily life [14-16]. The pain, psychological and social dysfunction subsequently impairs the quality of life and decreases professional productivity [17]. As there is no clear cause or cure, the disease is likely to be chronic and recurrent. The potential impact on sexuality and fertility has a continuous negative effect on partnership.

Symptomatic hormonal therapies and analgesics can be effective in endometriosis-associated pain [18], but there is no evidence that these treatments improve fertility. In fact, many of those hormone-influencing medical treatments inhibit ovulation. In clinical practice, surgical procedures such as laparoscopy are required to confirm the diagnosis and to surgically resect the lesions. This procedure can be useful in reducing pain [18] and improving fertility in stage I or II [19], even in stage III or IV [20].

Managing endometriosis requires consideration of one of the most crucial problems experienced in gynaecology today: adhesion formation. Adhesions adversely affect fertility by influencing adnexal anatomy and gamete- as well as embryo transport [21], and surgery in endometriosis is thought to be a major cause of adhesion formation. Surgically-induced adhesion formation awareness [22] and the knowledge of adhesion-reducing standards are only mainly seen by minimal-access surgeons [23]. The ESGE Adhesions Research Working Group [24] and the European Society of Human Reproduction and Embryology [25] recommend the consistent use of an anti-adhesion standard and eventually adhesion prophylactic agents during endometriosis surgery [18] on a expert opinion level base of evidence.

In a society with growing health care costs and limited resources, health professionals, policy makers and insurance companies need to pay attention to the consequences of endometriosis and the role played by adhesions [26]. This knowledge should be taken into account to better assist women suffering from endometriosis and in coping with the effects of the disease on their daily lives.

Because endometriosis is under-diagnosed, under-reported and under-researched, the pathophysiology itself and the concurring disease-related adhesion formation lead to fertility changes making a global future plan necessary to improve endometriosis-, adhesions- and the related subfertility outcomes.

Acknowledgments The ANGEL Group, consisting of experts out of nine different nations, has invested significant efforts and resources in improving general awareness and generating evidence on the clinical benefits of adhesion prophylaxis during the last 5 years; this work will be continued with a special impact on adhesion prophylaxis in endometriosis-related surgeries.

The ANGEL Group is a panel of European gynaecological surgeons focused on identifying opportunities to reduce the incidence of adhesions through collective expert proposals on actions to take to prevent adhesions.

The members of the ANGEL Group are: Dr. Julio Alvarez (Spain), Prof. Hans Brölmann (Netherlands), Dr. Rudi Campo (Belgien), Dr. Ying Cheong (United Kingdom), Prof. Philippe Koninckx (Belgium), Prof. Per Lundorff (Denmark), Prof. Leszek Pawelczyk (Poland), Prof. Horace Roman (France), Dr. Attilio di Spiezio Sardo (Italy), Dr. Markus Wallwiener (Germany), Prof. Rudy Leon De Wilde (Germany).

\section{Compliance with ethical standards}

Funding This study was funded by NORDIC Pharma Europe.

Conflict of interest All authors received reimbursement of travel expenses and accommodation costs by NORDIC Pharma Europe.

Human and animal rights This article does not contain any studies with human participants or animals, performed by any of the authors.

\section{References}

1. Eskenazi B, Warner ML (1997) Epidemiology of endometriosis. Obstet Gynecol Clin N Am 24:235-258

2. Meuleman C et al (2009) High prevalence of endometriosis in infertile women with normal ovulation and normospermic partners. Fertil Steril 92:68-74

3. Verkauf BS (1987) Incidence, symptoms, and signs of endometriosis in fertile and infertile women. J Fla Med Assoc 74:671-675

4. Sanchez AM, Vigano P, Somigliana E, Panina-Bordignon $\mathrm{P}$, Vercellini P, Candiani M (2014) The distinguishing cellular and molecular features of the endometriotic ovarian cyst: from pathophysiology to the potential endometrioma-mediated damage to the ovary. Hum Reprod Update 20:117

5. Young VJ, Brown JK, Saunders PTK, Horne AW (2013) The role of the peritoneum in the pathogenesis of endometriosis. Hum Reprod Update 19:558-569

6. Gazvani R, Templeton A (2002) New considerations for the pathogenesis of endometriosis. Int J Gynaecol Obstet 76:117-126

7. Iwabe T, Harada T, Terakawa N (2002) Role of cytokines in endometriosis-associated infertility. Gynecol Obstet Invest 53(Suppl 1):19-25

8. Matsuzaki S, Schubert B (1998) Oxidative stress status in normal ovarian cortex surrounding ovarian endometriosis. J Reprod Med 43(3 Suppl):269-275

9. Agarwal A, Aponte-Mellado A, Premkumar BJ, Shaman A, Gupta S (2012) The effects of oxidative stress on female reproduction: a review. Reprod Biol Endocrinol 29(10):49. doi:10. 1186/1477-7827-10-49

10. Hamdan M, Dunselman G, Li TC, Cheong Y (2015) The impact of endometrioma on IVF/ICSI outcomes: a systemati review and meta-analysis. Hum Reprod Update 2:809-825

11. Hamdan M, Omar SZ, Dunselman G, Cheong Y (2015) Influence of endometriosis on assisted reproductive technology outcomes: a systematic review and meta-analysis. Obstet Gynecol 125:79-88

12. Wallwiener M, Brölmann H, Koninckx PR, Lundorff P, Lower AM, Wattiez A, Mara M, De Wilde RL (2012) Adhesions after abdominal, pelvic and intra-uterine surgery and their prevention. Gynecol Surg 9:465-466

13. Lundorff $\mathrm{P}$, Brölmann $\mathrm{H}$, Koninckx $\mathrm{P}$, Mara M, Wattiez A, Wallwiener M, Trew G, Crowe A, De Wilde RL (2015) Predicting formation of adhesions after gynaecological surgery- 
development of a risk score. Arch Gynecol Obstet. doi:10.1007/ s00404-015-3804-0

14. Simoens S et al (2012) The burden of endometriosis: costs and quality of life of women with endometriosis and treated in referral centres. Hum Reprod 27(5):1292-1299

15. Noaham KE, World Endometriosis Research Foundation Global Study of Women's Health Consortium et al (2011) Impact of endometriosis on quality of life and work productivity: a multicenter study across ten countries. Fertil Steril 96:366-373

16. De Graaff AA et al (2013) The significant effect of endometriosis on physical, mental and social well-being: results from an international cross-sectional survey. Hum Reprod 28(10):2677-2685

17. Gao X et al (2006) Health-related quality of life burden of women with endometriosis: a literature review. Curr Med Res Opin 22(9):1787-1797

18. Dunselman G et al (2014) ESHRE guideline: management of women with endometriosis. Hum Reprod 29(3):400-412

19. Marcoux S, Maheux R, Bérubé S (1997) Laparoscopic surgery in infertile women with minimal or mild endometriosis. Canadian Collaborative Group on Endometriosis. N Engl J Med 337(4):217-222

20. Schenken RS (1998) Modern concepts of endometriosis. Classification and its consequences for therapy. J Reprod Med 43(3 Suppl):269-275
21. ASRM (2013) Pathogenesis, consequences and control of peritoneal adhesions in gynecologic surgery: a committee opinion. Fertil Steril 99(6):1550-1555

22. Herrmann A, De Wilde RL (2015) Adhesions are the major cause of complications in operative gynaecology. Best Pract Res Clin Obstet Gynaecol. doi:10.1016/j.bpobgyn.2015.10.010

23. Wallwiener $\mathrm{M}$ et al (2014) A European survey on awareness of post-surgical adhesions among gynecological surgeons. Gynecol Surg 11:105-112

24. De Wilde RL et al (2014) Consensus recommendations on adhesions (version 2014) for the ESGE Adhesions Research Working Group (European Society for Gynecological Endoscopy): an expert opinion. Arch Gynecol Obstet 290:581-582

25. ESHRE Endometriosis Guideline Development Group. Management of women with endometriosis. September 2013

26. Hirschelmann A, Tchartchian G, Wallwiener M, Hackethal A, De Wilde RL (2012) A review of the problematic adhesion prophylaxis in gynaecological surgery. Arch Gynecol Obstet 285:1089-1097 